\title{
Teaching English Grammar Communicatively: Theories, Principles and Implications in English Teaching in Vietnam
}

\author{
Cam T. H. Khuong ${ }^{1}$ \\ ${ }^{1}$ School of Global, Urban and Social Studies, RMIT University, Australia \\ Correspondence: Cam T. H. Khuong, RMIT University, Melbourne, Australia. E-mail: hongcam0604vn@yahoo.com
}

Received: June 22, 2015 Accepted: June 30, $2015 \quad$ Online Published: July 2, 2015

doi:10.5430/ijelt.v2n2p68 URL: http://dx.doi.org/10.5430/ijelt.v2n2p68

\begin{abstract}
In Vietnamese high schools, English is mainly taught under the Grammar Translation Method in order to help students get good results in grammar-oriented examinations. Therefore, in a long term, the students suffer from tiredness and failure to communicate in English properly. A conceptual framework of studying grammar is shaped with a view that grammar should be studied in context. Following this theoretical stance, principles and implications for grammar teaching are formed to enhance students' communicative competence and their interest in learning grammar.
\end{abstract}

Keywords: Communicative, grammar, English teaching, language in context, Vietnam

\section{Introduction}

English has become a compulsory subject in all high schools in Vietnam to provide students with a new tool of communication to absorb scientific knowledge, advanced technologies and diversified cultures in the globalization era. However, the reality of English teaching and learning is problematic and after seven years of its learning, Vietnamese high school students still fail to use even common and simple sayings to communicate (Phuong \& Uyen, 2014). One of the detected problems in the teaching of English at high schools is grammar dominated exams (Toan, 2013) and, consequently, the teachers' over-use of Grammar Translation Method (Ho \& Binh, 2014). In order to enable the students to use grammatical structures to communicate properly and motivate them to learn grammar, it is necessary to examine a theoretical framework on which the teaching of communicative grammar will be grounded. This paper, hence, focuses on the three main points of (i) nature of the study of language, (ii) principles derived from this understanding, and (iii) implications for communicative grammar pedagogy.

\section{Nature of Language}

This section investigates the nature of language in terms of the study of language and grammar as one of its aspects.

\subsection{Two Paradigms in the Study of Language}

The study of grammar - a particular linguistic level - can be thoroughly conducted only if it is positioned in a broader conceptual framework, i.e. the study of language. Therefore, this part will first examine the nature of the study of language in two contrastive views - as an autonomous system and as socially embedded - to identify which model grammar should be studied in later.

\subsubsection{Language as an Autonomous System}

In the first paradigm, language is considered as an abstract system which is constituted by rules that interact to determine its form and intrinsic meaning. Hence, this system can exist independently of its social context. Two dominant supporters of this view are Ferdinand de Saussure and Noam Chomsky.

Ferdinand de Saussure - the father of modern linguistics and the founder of structuralism - was the first to propose his view in his 1916 posthumous work which was then translated as Course in General Linguistics in 1959 (Saussure, 1916). He made a clear-cut distinction between "langue" (language) and "parole" (speech), which both formed "langage" (human speech). Langue is taken as the system of rules and conventions which are independent of, and 
pre-exist, individual users; parole refers to its use in particular cases. However, Saussure only considers langue as the object of the study of language and rejects the role of parole inasmuch as the later is too complicated.

Similarly, Chomsky argues that language can exist without its context of use, stating that it is mentally rather than socially constructed. It is a property of the individual human mind, which, in its turn, is the product of "an innate, genetically determined features of the human species" (as cited in Cook, 2003, p. 41). In brief, this perspective claims that the study of language can be systematically implemented without its social context.

\subsubsection{Language as Socially Embedded}

The other side of the coin is the standpoint that language can be properly studied as a social phenomenon. In this angle, language does not exist as an end in itself but is socially constructed, since it functions as a means that human beings employ to communicate their meanings. Therefore, its study is inseparable from its social context with various components determining the understanding of its meaning. Different researchers from various fields of study at different times all share the same perspective on this issue.

Malinowski (1946), an anthropologist, was the first to emphasize the importance of contextualization in the study of language. Specifically, he argued that language use was embedded in a "context of situation" within which utterances became meaningful and comprehensible and that language was "functional" (employed to perform certain functions in society) and "semantic" (concerned with how language means) (as cited in Eggins, 2004, p. 88). All the significance of Malinowski is summarized in the following words:

A statement, spoken in real life, is never detached from the situation in which it has been uttered. For each verbal statement by a human being has the aim and function of expressing some thought or feeling actual at that moment and in that situation, and necessary for some reason or other to be made known to another person or persons - in order either to serve purposes of common action, or to establish ties of purely social communion, or else to deliver the speaker of violent feelings or passions... utterance and situation are bound up extricably with each other and the context of situation is indispensable for the understanding of the words.... a word without linguistic context is a mere figment and stand for nothing by itself, so in reality of a spoken living tongue, the utterance has no meaning except in the context of situation. (ibid., p. 88)

From his perspective, language is only meaningful when it is interpreted within its context and it is functional since it is used for a certain purpose.

After over thirty years, from a linguistic perspective, Firth (1957) extended the notion of context of situation to the more general issue of linguistic predictability with a claim that a given description of context can help people predict what language will be used. He maintained "once someone speaks to you, you are in a relatively determined context and you are not free just to say what you please" (p. 28). The predictions are determined by the following elements of the context of situation, as he explicitly pointed out:

A. The relevant features of participants: person, personalities

i) The verbal action of the participants.

ii) The non-verbal action of the participants.

B. The relevant objects

C. The effect of the verbal action. (p. 182)

These factors need taking into consideration since they make the meaning of language understandable. As such, Firth, in more detail, supported Malinowski's view that language is functional and semantic.

Based on the theory of his teacher Firth, Halliday (1994) developed systemic-functional linguistics (SFL), which is a theory of language centered around the notion of language function. While SFL accounts for the syntactic structure of language, it places the function of language as central in preference to structural approaches, which place the elements of language and their combinations as central. SFL starts at social context, and looks at how language both acts upon and is constrained by this social context. Specifically, in Halliday's perspective, the social context refers to what is going on in the specific situation in which the text, a piece of language in use, occurs and makes what the text is. The differences between one text and another depend on three aspects of context: field (what is to be talked or written about), tenor (the relationship between the speaker and hearer or writer and reader) and mode (the kind of text - spoken or written - that is being made), which collectively define the situational context of a text (Halliday \& Hasan, 1990, p. 22). Three factors of context of situation accordingly affect the choices of language since they reflect its three main functions: ideational (language as form and meaning), interpersonal (language as communication) and 
textual function (language as text) respectively (ibid., pp. 26-27). In sum, Halliday inherited the view that language is functional and is dependent on its situational context for its proper understanding from his predecessors and developed it in a thorough and insightful way.

In short, the researchers from various disciplines, namely anthropology, sociolinguistics and linguistics, have all advocated the view that language should be studied concurrently with its social context due to the significance of context and contextual components for full comprehension of language.

\subsection{Grammar as One Aspect in the Study of Language}

Language is a system that comprises four main sub-systems of grammar, vocabulary, morphology, and phonology. Since grammar is one aspect of language, its study also corresponds to the two previously presented paradigms.

\subsubsection{Two Paradigms in the Study of Grammar}

Two paradigms of language as an abstract system and as a social phenomenon respectively entail two models of grammar: form-based and function-based.

\subsubsection{Form-based Grammars}

Grammars based on the theory of language as an autonomous system includes traditional grammar, transformational-generative grammar and case grammar.

Traditional grammar is a theory of the structure of language based on ideas Western societies inherited from ancient Greek and Roman sources (Sharma, 2005). In the traditional grammarians' perspectives, a grammar should provide a set of rules for correct language use and the correctness was judged through the rules of the grammar of Latin. Specifically, this model "relies on categorizing words into parts of speech; describing grammatical relations such as subject, predicate, and direct object; and recognizing natural groupings (constituents) such as phrases, clauses and sentences" (Barry, 2002, p. 63).

This type of grammar is completely formal and, hence, contains in it various drawbacks. For instance, it is "normative and prescriptive rather than explicit and descriptive" (Sharma, 2005, p. 85). Similarly, it specifies the correct way of using language without context rather than provides descriptions of the actually spoken language. In the same vein, it

tended to assume not only that the written language was more fundamental than the spoken, but also that a particular form of the written, namely the literary language, written and spoken; and that it was his task, as a grammarian, to preserve this form of language from corruption. (Lyons, as cited in Sharma, 2005, p. 87).

Another representative of the form-based model is transformational-generative grammar generated by (Chomsky, 1968). The main purpose of his model is to describe the basis transformation necessary to create permissible sentences in any given language. His idea was clarified as follows:

$\ldots$ the grammar of a language must contain a system of rules that characterizes deep and surface structures and the transformational relation between them, and - if it is to accommodate the creative aspect of language use that does so over an infinite domain of paired deep and surface structures. (p. 15)

As such, transformational-generative grammar definitely focuses on linguistic competence. Therefore, like traditional grammar, it does have some limits. Although an infinite number of grammatical sentences can be generated, the formation of rules excludes the generation of grammatically incorrect sentences. Well-formness is a must, which is against the reality that very few people know grammar perfectly or use it correctly at all time. Furthermore, the syntactic analysis cannot deal with non-factual meaning that can only be examined in the social context of language.

A branch of transformation-generative grammar is case grammar that was first put forward by Fillmore (1968) in reaction to the lack of semantic roles played by words in a sentence within Chomsky's grammatical model. Case grammar is a system of linguistic analysis focusing on the link between what is termed "deep structure" in transformational grammar such as subject, verbs and objects and the semantic roles or "cases". The term "case" was clarified by Fillmore (1968, p. 24) as follows:

the case notions comprise a set of universal, presumably innate concepts which identify certain types of judgments human beings are capable of making about the events that are going on around them, judgments about such matters as who did it, who it happened to, and what got changed. 
Hence the case is used to identify the universal underlying syntactic-semantic relationship. As such, although this model challenges the previous form-based ones with regard to the semantic roles, it still inclines more to the formal end of the form-function continuum in the study of grammar, since it deals with language at the level of sentence and considers meaning of language as universal and isolated from the social context.

\subsubsection{Function-based Grammars}

If the form-based grammars deal with language at the level of sentence and linguistic competence, the function-based ones operate at that of text and are concerned with communicative competence in the way that the meaning of language is always considered in its social context. To put it simply, they aim to match forms to function and meaning in context. The paradigm of socially grounded grammars includes two main grammatical types of systemic-functional grammar and discourse grammar.

Systemic functional grammar, which originated from the theory of systemic functional linguistics, deals with both written and spoken language with all text types that are used to achieve the social purposes. In other words, it describes the way grammar functions in spoken and written texts and what it does with the meaning of text. Specifically, "everything in the grammar can be explained, ultimately, by reference to how language is used" (Halliday, 1994, p. xiii) and systemic functional grammar has an aim to "construct a grammar for purposes of text analysis: one that would make it possible to say sensible and useful things about my text, spoken or written, in modern English" (p. xv).

In this model, the clause, not the sentence, is considered to be the basic choices which are socially grounded and "represent the meaning potential of any given language" (McCarthy, 2001, p. 59). The choices of certain part of speech within the grammatical system are dependent on social concerns. Therefore, although this grammatical model sounds opposite to form-based ones, it does not "reject, discard or replace terminology of traditional grammar" (Butt, Fahey, Spink, \& Yallop, 1995, p. 31). Actually, the notion of traditional grammar is built on and refined in a systemic functional way which means that each linguistic element is not seen as isolation but in relation to others.

Another distinct function-based theory is discourse grammar. This model has an explicit stance against Chomskyan one in the manner that it denies the view of grammar as an autonomous system and emphasizes the effects of the context of verbal interaction in the form of discourse on linguistic structure. Specifically, a clear-cut distinction between discourse-based and sentence-based grammars is that the former makes "strong connection between form, function, and context and aims to place appropriateness and use at the center of its description" (Hughes \& McCarthy, 1998, as cited in Paltridge, 2006, p. 129). What is more, it also "acknowledges language choice, promotes awareness of interpersonal factors in grammatical choice, and can provide insights into areas of grammar that previously lacked a satisfactory explanation" (p. 129).

Similarly, this type of grammar views "grammatical meaning as interactively determined rather than being inherently 'in' the structure under scrutiny. It is clear that such a view of grammar is well out of kilter with an idealized, sentence-based, Chomskyan approach to language description ..." (McCarthy, 2001, p. 106). In fact, it ideally aims to serve a view of language as socially embedded.

The value of discourse-based grammar over the formal ones is highly appreciated by Celce-Murcia along with Larsen-Freeman (1991) with an argument that the mere focus on grammatical form without considering its functional meanings in discourse "paints only an impoverished picture of language" and "fails to unite grammar with its use in interaction" (as cited in McCarthy, 2001, p. 109).

\subsubsection{The Concept of Context}

As presented above, a significant characteristic of the function-based framework is that it takes very seriously the fact that a grammatical structure is produced and understood in context. Thus, this concept is of importance in making a grammatical item comprehensible. However, the presented theories about context are complicated. Given this fact, the aim of this section is to articulate how context is treated and described in a particular way that is closely related to the study under investigation.

Hymes $(1972,1974)$ proposes a conceptual framework to study the concept of context, which consists of eight main factors in the acronym SPEAKING: Situation (Setting and Scene), Participants, Ends, Act sequence, Key, Instrumentalities, Norms and Genres (as cited in Widdowson, 2004, pp. 41-42). Of these components, relevant to this paper are setting, participants and purposes. As these key contextual components all govern the meaning and appropriateness of a grammatical item, they will be deeply explored in turn to show their influence on the language choices. 


\subsubsection{Setting}

Setting is defined by Hymes (1974, as cited in Widdowson, 2004, p. 42) as "the time and place of a speech act" and generally as "the physical circumstances". This factor plays an important role in making differences in the way people use and perceive language. Specifically, in each possible location and at certain time, a speech community will have a particularly unwritten idea about what conversation or discourse is normally accepted, what can be said and what is appropriate and not appropriate. A particular setting can also affect the specific kinds of responses people are likely to make. On the contrary, the meaning of an utterance can also change depending on the setting. Hence, it is necessary to take this element into consideration due to its influence on the production and perception of language.

\subsubsection{Participants}

The choice of a grammatical item also depends on who is participating in the language exchange, i.e. participants, since "language is not used in a vacuum but by one person to another" (Lewis \& Hill, 1985, p. 22). Specifically, participants in a speech event include speaker-listener, speaker listening, audience and sender recipient (Hymes, 1972, as cited in Jacobson, 2008, p. 14). In the interaction between a speaker and listener, participants can switch their roles as being a listener to a speaker and vice versa. Furthermore, they can switch from one of four skills, namely listening, reading, speaking or writing, to another, or they are engaged in an activity that involves simultaneously employing several skills (Celce-Murcia \& Olshtain, 2000, p. 3). Finally, participants' characteristics such as social status, age, sex, and relationships with each other directly affect a person's speech and his or her relationships to the means of communication as well (Saville \& Troike, 1989, as cited in Jacobson, 2008, p. 15).

\subsubsection{Purposes}

In addition to setting and participants, the choice of language is essentially dependent on what the speaker or writer wants to do with the language, or, in other words, what purposes, or ends the speaker or writer wants to achieve (Hymes, 1972, as cited in Jacobson, 2008, p. 15). Ends include the outcomes of the event itself and the individual goals of the participants. The speech event in a community may vary depending on the nature of such events and on specific meanings attached to them. Hence, the choice of language also varies to serve those purposes.

In short, context in the study of grammar must also consist of three main components, namely setting, participants and purposes, to enable the students to understand the target structure fully. Specifically, a grammatical item needs to be contextualized by including the time and the place when and where the structure is employed by those who want to use it for a particular purpose. Hence, context can be simply understood as either spoken or written texts and the physical surroundings in the classroom that meet those requirements.

\section{Principles for Grammar Pedagogy}

In the previous section, the nature of language has been dwelt upon in some depth. It reveals that language in general and grammar in particular should be studied concurrently with its social context rather than autonomously as an abstract system. Following it, this part will explore how the theory works in the practice of grammar teaching.

\subsection{Principles for Creating Context for Grammar Teaching}

The way to bring context in grammar lessons should be carefully considered to get the desirable results in its teaching and learning. A good context must have three characteristics of authenticity, informative background provision, and interest attraction.

First, the appropriateness of context can be achieved if the teacher brings something "real" and "useful outside the classroom" (Lewis \& Hill, 1992, p. 28). Second, context should "provide the background for a lot of language use so that students can use the information not only for the repetition of model sentences but also for making their own sentences" (Ur, 1996, p. 57). In other words, it should supply enough data for learners to explore the form and meaning of the target structure for themselves to reproduce it later. Especially, an informative context should follow the following principles:

- The context should be easily recognizable and comprehensible one.

- It should provide lots of clues as to the meaning of the target item.

- It should help eliminate other, competing meanings.

- There should be more than one example of the item if possible (but not so many that the text sounds unnatural). 
- The item should be displayed in a variety of forms. (ibid., p. 57)

Finally, context should attract students' interest. Figuratively, it should be made "seductive" in the way that the students cannot resist it but they have to "dig" it and "get their hand dirty" (Ehrenworth \& Vinton, 2005, p. 89).

\subsection{Principles for Creating Tasks for Grammar in Context}

Generally speaking, when grammatical structures are taught, teachers are, or should be, asking students to learn "a large number of different though related bits of knowledge and skills" (Ur, 1988, p. 6) which are recognition, identification and production of the target structure. Specifically, they have to know how to recognize the examples of the structure from a spoken or written text, how to identify its form and meaning in context, how to produce both its written and spoken form and meaningful sentences in appropriate context using it themselves. Therefore, teachers need to include context while designing tasks for presenting, practicing and consolidating the target structure. This means that they necessarily contextualize the structural forms and integrate one or more communicative skills in all teaching stages, namely Presentation, Practice and Production (3Ps). The models for these 3Ps stages will be specifically elaborated on in the following parts.

\subsubsection{Model of Presentation}

The aim of the presentation is to introduce students the form and meaning as well as the appropriate use of a new piece of language in both speech and writing (Harmer, 1991). This stage is of importance to the process of learning a structure since it helps students take the grammatical point into their short-term memory and equips them with necessary input for the communicative activities at the later stages (Harmer, 1991, p. 56). Without this phase, the teacher has to interrupt students for explanations and corrections, which is synonymous to the lack of time for actual practice (Ur, 1988, p. 7).

When conducting this stage, teachers should replace traditional procedure in which rules of a grammatical item are explained before examples of its actual use. They, in a reversed way, should provide the students with an opportunity to discover the underlying pattern through context (Ehrenworth \& Vinton, 2005; Harmer, 1991). To do this, they can give them a reading or listening (i.e. written or spoken) text which contains the target structure and let them do some "problem-solving" tasks individually or in pairs or groups with the text to discover by themselves what the pattern is and how it works in that context (Harmer, 1991, pp. 71-72). This procedure attracts their attention to the meaning and use before the form of the target structure. This shift aims to make the concept become clearer and help them achieve noticing within a rich environment of communication. After they finish the tasks, the teacher will ask them what they have found and discuss the answers with them to clarify the form, meaning and use of the target structure, which is implicitly the explanation stage.

The model above has some pedagogical merits. The fact that students discover the language point themselves rather than being told underlying patterns can positively affect their "retention" (Shaffer, 1989, p. 401), since they are more "involved" and their "reasoning process" is encouraged (Harmer, 1991, p. 71). Furthermore, their roles are more active than the teacher's, which can considerably enhance their interest and reduce their tension which the previous dictatorial roles of teacher brought to them in traditional grammar lessons. After the target structure is presented, it should be practiced to transfer what the students know "from short-term to long-term memory" (Ur, 1988, p. 7).

\subsubsection{Model of Practice}

The aim of this stage, specifically, is to help students further absorb the form of the structure and the focus at this stage is on the accuracy of what the students are saying and writing (Harmer, 1991; Ur, 198).

To achieve that aim, controlled activities are designed. However, in the method under discussion, although practice tasks retain focus on correct production, they need to ensure to sound "communicatively authentic" and lead learners to recognize the "communicative function" of the grammatical form (Littlewood, 1981, pp. 10-11).

Therefore, necessary attention should be paid to the techniques of designing the controlled practice in context. Traditionally, much practice with sentence-based exercises creates many students who can learn to successfully complete those exercises but remain unable to appropriately use the features practiced. Thus, Lock (1996, pp. 275-276) suggested giving practice at text level, holding that text-based practice, either in speech or writing, strongly associates structure with its meanings in context; hence, it likely enables learners to produce proper items in similar contexts in later occasions.

In designing tasks for this stage, teachers can modify the mechanical exercises in the textbooks by requiring the students to deal with texts rather than isolated sentences or they can create the tasks themselves in the same way. They can employ any of the following tasks for this improvement: 
- In text completion: students have to pay attention to features of contexts in order to select appropriate items to complete a text.

- In text sequencing: students have to pay attention to the relationship between grammar and context to sequence out-of-order units of a text. This is particular useful for focusing on reference and thematic organization but it can be used for focusing on sequence of tenses.

- Text transformation involves recasting texts in different contexts and communicative purposes.

- Text reconstruction combined with information transferred. The students can depend on a prompt to reconstruct a text. (ibid., pp. 275-276)

The tasks that Lock suggested can be employed for practicing the writing skills. In terms of oral practice, teachers can make use of activities such as information gaps, games and oral interaction recommended by Harmer (1991, pp. 92-108). Specifically, in information gaps, different students are given different pieces of information for sharing with their partners to complete the task. This activity can give the students the real purpose to communicate. Another activity is games which can be used to practice the language in any stage of the lesson to provide the students with relaxation from other classroom activities. In this stage, games are more controlled in the way that the level of language practiced is limited. The last activity, oral interaction, can help students practice particular language in an active and enjoyable way. Students are asked to interact with their partners by asking and answering based on the teachers' prompts.

The tasks that are designed in these ways definitely help students practice the accurate structural forms simultaneously with communicative purposes, but they are more controlled in what to say or write. In order to fulfill these tasks, students can be required to work individually or in pairs to write or talk, depending on what activity they are doing. Teachers can slightly intervene to give the students some immediate guide if their language is not formally accurate (Harmer, 1991, p. 50).

The stage of controlled practice is then followed by free practice or, in order words, the production stage.

\subsubsection{Model of Production}

This stage, which most textbooks are devoid of, is the most productive, and hence, the most exciting one (Ur, 1988, p. 8). While the controlled practice in the previous stage deals with the accurate form, the free one in this stage focuses on achieving its meaning and fluency in communicating.

Due to such a shift in focus from accuracy to fluency, the tasks designed for this stage should accordingly be different from those in the previous one in the way that they should make learners perform more freely and "less controled by the specific prompts but more controled by the need to produce language in response to the functional and social demands of social interaction" (Littlewood, 1981, p. 10). To put it another way, the activities should be able to give the students a real purpose to communicate as well as a better chance to engage themselves in "a varied use of language" so that they can "do their best to use the language as individuals, arriving at a degree of language autonomy" (Harmer, 1991, p. 51). In order to design communicative tasks like those, teachers should also consider the elements of context like the practice tasks but at the higher level of challenge and freedom. For example, teachers can make use of some of the practice tasks by Lock (1996, p. 276) as presented above to develop communicative activities in this stage such as text transformation or text reconstruction or even text creation in which the learners produce complete texts either collaboratively or individually. It should be noted that the patterns of production tasks can be similar to those of the practice ones but the difference lies in the fact that prompts are much reduced for the students to use their own language they possess to complete the tasks.

Likewise, teachers can adapt the communicative activities suggested by Harmer (1991, pp. 122-139) such as discussion, communication games, information exchanges about the students themselves, or role-play in accordance with the suitability of the target grammatical points.

As far as discussion activity is concerned, teachers should put the students into groups for them to feel at ease to do the task, and then let them have time to prepare for a specific task. This activity can bring much success to the grammar lesson at this stage if they know how to conduct it. Another activity of communication games is based on the principles of information gaps in which the students are put in a situation that they have to use their own language stock to fulfill the game-like tasks. Similarly, exchanging information about the students themselves can result in satisfactory outcomes since they are a valuable resource that can be used for various interpersonal exchanges. Finally, role-play functions as a reproduction of situations like real life in the classroom. It means that the students must pretend to be someone else in the given situations and use the language to fulfill a given task, but not a real student in the classroom. 
These recommended communicative tasks should be flexibly combined and designed for the suitability of the particular target and can be conducted in either spoken or written form.

During this stage, teachers can also ask students to work individually, in pairs or groups. Pair work and group work are more favorable since students have a chance to use language to communicate with their peers (Harmer, 1991, pp. 122-139). Moreover, since the appropriacy of using language has more attraction in communication than the well-formedness, greater emphasis of corrective feedback is put on mistakes that hinder fluent communication than on those concerned with accurate forms (Littlewood, 1981, p. 91). Therefore, correction should be delayed to be corrected later so as not to prevent learners from communicating (Harmer, 1991, p. 238).

In brief, the principles for task design in the three stages show that the form, meaning and use of a target structure should be introduced, practiced and consolidated with the embedded context. Ideally, four skills should be simultaneously integrated in each stage.

\section{Implications for Communicative Grammar Teaching in Vietnamese High Schools}

This section elaborates on a model of teaching grammar implicated from the theory of language in general and grammar in particular and princples derived from this theory for a Vietnamese high school so that students can acquire grammatical structures effectively and make use of them in communication for the fulfilment of communicative purposes. The 3Ps stages of a grammar lesson still needs to be maintained but further improved in the way that the grammar items can be taught concurrently with context through communicative tasks.

Specifically, at the presentation stage, teachers should give an authentic listening text for the students to do a listening task. Then the listening transcript will be used as a reading text for them to find answers to discovery questions which explore their understanding about the form, meaning and use of the target structure. This technique can be conducted in pairs or groups so that they can learn from each other and have chances to use language in communication to achieve the task. Teachers then give feedbacks and some necessary explanations if any of the form, meaning and use of structure are quite out of their depth.

After the presentation, teachers will create controlled practice tasks that are based on the principles provided to help the students practice the form of the structure, but in a communicative way. They will move away from the exercises with isolated sentences in the textbook and let them practice at the text level with the real purposes, participants to use the mechanism to exchange meaning. They can do these activities individually and then work in pairs or groups to exchange ideas. During this stage, teachers will interfere in their performance, if necessary, to give some help. If the target structure is inappropriately produced, they can signal the mistakes on the spot or later with the whole class.

At the production stage, teachers will give communicative activities for the students to produce the learned structure to achieve some communicative purposes that are required. Pair work and group work will be employed. When these activities are in process, teachers will walk around for necessary help and take notes on the mistakes that obstruct the communication and correct them with the whole class at the end of the stage.

\section{Conclusion}

This paper has shaped a conceptual framework in three main sections. The theory in this paper is the view that language in general and grammar in particular should be learned in context with the three main components of setting, participants and purposes. From that theory, principles for grammar pedagogy, both for creating context and designing tasks in the three stages of presentation, practice and production, are presented. Based on both the theory and principles, the implications for teaching grammar communicatively in the three stages are outlined.

\section{References}

Barry, A. K. (2002). Linguistic perspectives on language and education. Westport: Greengroup Publishing Group Inc.

Butt, D., Fahey, R., Spink, S., \& Yallop, C. (1995). Using functional grammar: An explorer guide. Sydney: Macquarie University.

Celce-Murcia, M., \& Olshtain, E. (2000). Discourse and context on language teaching: A guide for language teachers. Cambridge: Cambridge University Press.

Chomsky, N. (1968). Language and mind. Cambridge: Cambridge University Press. 
Cook, G. (2003). Applied linguistics. Oxford: Oxford University Press.

Eggins, S. (2004). An introduction to systemic functional linguistics. New York: Continuum International Publish Group.

Ehrenworth, M., \& Vinton, V. (2005). The power of grammar: Unconventional approaches to the conventions of language. Portsmouth: Heinemann.

Fillmore, C. J. (1968). The case for case. In E. Bach, \& R. Harms (Eds.), Universals in linguistic theory. New York: Holt Rinehart \& Winston, Inc.

Firth, J. R. (1957). Papers in linguistics. London: Oxford University Press.

Halliday, M. A. (1994). Introduction to functional grammar (2nd ed.). London: Edward Arnold.

Halliday, M. A. K., \& Hasan, R. (1990). Cohesion in English. Harlow: Longman.

Harmer, J. (1991). The practice of English language teaching. Harlow: Longman.

Ho, P. V. P., \& Binh, N. T. (2014). The effects of communicative grammar teaching on students' achievement of grammatical knowledge and oral production. English Language Teaching, 7(6), 74-86. http://dx.doi.org/10.5539/elt.v7n6p74

Jacobson, R. (2008). The pulse of a Malaysian university: Ethno- and sociolinguistic issues and the TESOL dimension. New York: Peter Lang Publishing Inc.

Lewis, M., \& Hill, J. (1992). Practical techniques. London: Commercial Color Press.

Littlewood, W. (1981). Communicative language teaching: An introduction. Cambridge: Cambridge University Press.

Lock, G. (1996). Functional English grammar: An introduction for second language teachers. Cambridge: Cambridge University Press.

Paltridge, B. (2006). Discourse analysis: An introduction. New York: Continuum.

Phuong, T., \& Uyen, T. (2014). Why is the teaching and learning of English "treading water"? Vietnamnet. Retrieved $15 / 06 / 2015,2015$, from http://m.vietnamnet.vn/vn/giao-duc/214385/vi-sao-day-va-hoc-tieng-anh-mai--giam-chan-tai-cho-.html

Saussure, F. (1916). Course in general linguistics (A. Reidlinger \& W. Baskin, Trans. C. Bally \& A. Sachehaye Eds.). London: Owen.

Shaffer, C. (1989). A comparison of inductive and deductive approaches to teaching foreign languages. The Modern Language Journal, 73(4), 395-403. http://dx.doi.org/10.1111/j.1540-4781.1989.tb05319.x

Sharma, B. D. (2005). Language and linguistics. Dehli: Mehra Offset Press.

Toan, V. (2013). English teaching in Vietnam: Teacher 're-education'. Tuoi Tre News. Retrieved 15/06/2015, 2015, from http://tuoitrenews.vn/education/8231/english-teaching-in-vietnam-teacher-reeducation

Ur, P. (1988). Grammar practice activities: A practical guide for teachers. Cambridge: Cambridge University Press.

Ur, P. (1996). A course in language teaching: Practice and theory. Cambridge: Cambridge University Press.

Widdowson, H. G. (2004). Text, context, pretext: Critical issues in discourse analysis. Victoria: Blackwell Publishing. 